\title{
The main features of the web environment and the author's component of the journalist
}

\author{
L. Khavrychenko \\ National Technical University of Ukraine "Kyiv Polytechnic Institute" \\ Corresponding author. E-mail: luyda.khavr@gmail.com
}

Paper received 29.03.19; Accepted for publication 10.04.19.

\section{https://doi.org/10.31174/SEND-Ph2019-194VII58-08}

\begin{abstract}
The article is devoted to the review of modern information technologies and the main features of the web environment, as well as the operative author's work of the journalist when preparing content for Internet news. It is noted that news materials prescriptively used such forms of informative language, as a fact statements, a brief description of news and informative message. It is stated that distinctive properties of these types of broadcasting should be objective and impartial.

Keywords: mass media, internet news, journalism, multimedia, interactivity.
\end{abstract}

Introduction. Modern information Internet technologies provide relevance, selectivity, interactivity, and network multimedia. Moreover, it gives the possibility for the authors to fast writing of texts and the dissemination of journalistic products. The internet information can be regularly updated, for example, daily, hourly, etc. it depends on readiness of the materials. The information provides the ability to create and view archives. Interactivity of information on the news websites is the great ability for readers, who actively choose what they need, using e-mail, research data banks and archives, to participate in surveys and rating formation, as well as, in the form of teleconferences, chats, newsletters and guest books. The Multimedia information covers various forms of information transmission such as text, photo, sound, video and animation. [3]

All information in the web environment is subject to accounting and digital analysis. The sites have traffic counters that allow you to determine the exact number of views, geographic visits, track the dynamics of growth or decline in the popularity of the network resource. In turn, it helps to ascertain clearly possible target audience. Feedback with the audience provides interactivity web environment. Today, the existence of an online resource without interactive services becomes impossible. Because of the users, reaction to the message and dialogical character communications become the main condition of successful functioning of the site. [5]

Overview of publications on the topic. Various aspects of network media functioning were investigated by V. B. Potiatynik S. Kvit, G. Solganik [4], T. Petrova, V. Kikhtan [3]. M. Lukin, I. Fomicheva [6] investigated theoretical aspects of the Internet media functioning. S. Mashkova, L. Fedorchuk studied functions of network media. O. Kotsarev, O. Kolisnyk devoted their research to the network media typology. I. Nekrasov focuses mainly on the consideration of functions of mass media and its transformations that are connected with the active development of Internet technologies. Information technologies in Internet journalism were considered in works by $\mathrm{V}$. Kikhtan, V. Herasevich, L. Weber, E. Scott, A. Akopov [1] I. Tonkih [4]

Aim. The rapid development of the Internet has led to a diversification channel's information and a way of communication. Today, the network has a wealth of diverse resources, an important place among which is Media Segments. According to these trends, the journalist's profession itself undergoes significant changes. In addition, work in this area requires the mastering of the latest computer technologies. At the present stage, there is a need to explore and apply the new opportunities provided by the Internet. Our aim has resulted in the following tasks: to systematize the known theoretical approaches to the understanding of the features of texts in the media, in particular, Internet news; identify their leading role; study the language features of texts of Internet news; reveal the role and weight of the author's component in the process of creating the these texts.

Materials and methods. The material of our study is the text of Internet news taken from the $\mathrm{CNN}$ web site. In our article, we use a system-structured method that relates to media text and its genre internet news. Besides that, we used functional-stylistic method that explores the language features of the style of the mass media and provides an objective assessment of the media product in real terms, and helps to highlight the author's role in the creation of the media text, in particular, internet news.

Results and Discussion. It is hard to imagine a journalist's work without using the Internet. At the same time, the application of new information technologies takes place at all stages of the author's creative process. The journalist uses Internet technology to find information, prepare materials, as well as at the stage of their distribution and feedback with the audience. Thus, the Internet becomes a necessary source of information for the journalist, due to the network author finds a large number of news resources, sites of news agencies, official pages of organizations, reference and encyclopedic publications, archives of documents, scientific literature, etc. This information is used both for monitoring news and for the preparation of own materials, both for verification of materials for reliability, and for reference purposes. The main thing at the stage of information searching for the author becomes careful validation because it spreads over the network a large number of false, distorted facts. [4]

O. Akopov emphasizes that while identifying network media it is necessary to pay attention to the publisher, the purpose edition and target audience. [1] I. Fomicheva offers that for the identification of Internet media we can apply a five-member communication model, proposed by G.Lassuel: who speaks (communicator), speaking (content), for by means of which channel (means of communication), to whom to speak (audience) with what effect. The proposed scheme though is simplified, however it is 
convenient and efficient enough, and therefore can be used to identify network media In the case of the media it is always a professional communicator who has a certain education or no professional education, ma have been able to accumulate, process and analyze information.[6]

I. Fomicheva emphasizes the activity of communicators in this case, practically without exception, organized as corporate, collective. The collective of communicators is an editorial board of the online newspaper, specialized organization whose employees are professionals and actively working collecting, processing and distributing mass information. Collective communicator takes on an obligation on a certain legal, moral and ethical responsibility.

The reflection of reality in the texts of Internet news is an important task of a journalist, but journalism by its nature implies an understanding, an assessment of these facts, and, therefore, the presence of the author in the text. Reading the modern text of Internet news, the reader not only becomes an eyewitness of the events described, but also sees the text reflection of the author's personality, his self-consciousness, and creative individuality. Thus, the journalistic text, according to E.S. Shkolkunova, "is always" author's text ", regardless of how clearly the subject of the utterance is present in the text. The reader receives in the text the facts and their interpretation, even if it will be simply in the selection of information. [7]

The statement of fact is the main type of speech activity of the authors of news texts. The structure of the informative speech is subject to the following pattern: a fact statement is usually preceded by the informative narration or description, which in some cases can be the whole text, or in other case, it's part of an article's title or an article's lead. [2] The standard verbal form of factual utterance in the texts of the informative narration is a simple declarative sentence, mostly often affirmative. For example: Renton, Washington (CNN) Boeing unveiled an overhaul Wednesday to a software system and the pilot training of its signature 737 MAX plane, marking its most direct attempt to fix an element of the plane's original design that investigators believe led to two recent crashes. [8]

The construction of factual statements usually involves such language units, the semantics of which do not contain signs of subjective assessment or observed action, since the presence of such vocabulary signals the presence of the author, his point of view and personal perception of the incident. Therefore, here the key role is played by language units indicating a certain stage of the process such as negotiations have begun, the search continues, work has completed, etc.

The standards that form the style of news texts include verbs stating the speech-cognitive fact. Such verbs are usually included in syntactic constructions that have signs of repeatability and reproducibility, in particular, to negotiate; publish the results; a telephone conversation took place; consider the project; discuss the situation; give your opinion, etc.

In the expanded news report, after a statement of fact, an informative description may follow, which has specific features compared to other styles and genres. [2] Describing objects, phenomena, events, the author does not transmit his attitude to the objects or subjects, but expresses his logical assessment. Thus, the informative description fixes the objective existence of any property, that is, external, internal, physical, psychological. e.g. At the company's plant in Renton, Washington, where the plane is assembled, Boeing pilots ran through scenarios on a flight simulator that was transmitted live into a conference room where regulators and some 200 pilots from client airlines were gathered, according to Mike Sinnett, Boeing's vice president for product strategy. The guests were able to request test simulations. [8]

Informative description is aimed at forming characteristics of the object in terms of novelty and relevance, which is very important for creating news value such as new, old, last, recent, fresh; social status such as official, private, informal, business, friendly; geographical location, in particular, Russian, European, American; utility, for example, important necessary, significant. Verbs that indicate the nature of any relationship between objects or subjects such as define, mean, have, make, follow, cooperate, lead, prevent, facilitate, etc. have a high frequency in the informative description.

The third component of the informative speech used in the news media materials is an informative narration that conveys a sequence of actions or events. The narration in the news, focused on the informative type of speech, also has its own characteristics, because in the speech form verbs are not used, denoting the observed action. Thus, there are no signs of the manifestation of the author's "I am." Informative narrative complements, expands information, and therefore the narration becomes a kind of continuation of the fact statement.

For example, At back-to-back hearings in Washington on Wednesday, Trump administration officials were grilled about the decision to defer large parts of the 737's safety certification to Boeing.

Transportation Secretary Elaine Chao said Wednesday that she found it "very questionable" that safety systems were not part of the standard package offered by Boeing on its 737 Max jets.

"It is very questionable if these were safety oriented additions why they were not part of the required template of measures that should go into an airplane," she said in testimony before the Senate, where she was appearing to answer questions about her annual budget request.

But Chao defended the decision of the Federal Aviation Administration not to ground Boeing's signature plane after the first of two fatal crashes.

At back-to-back hearings in Washington on Wednesday, Trump administration officials were grilled about the decision to defer large parts of the 737's safety certification to Boeing.

Transportation Secretary Elaine Chao said Wednesday that she found it "very questionable" that safety systems were not part of the standard package offered by Boeing on its 737 Max jets.

"It is very questionable if these were safety oriented additions why they were not part of the required template of measures that should go into an airplane," she said in testimony before the Senate, where she was appearing to answer questions about her annual budget request.

But Chao defended the decision of the Federal Aviation Administration not to ground Boeing's signature plane after the first of two fatal crashes. 
At back-to-back hearings in Washington on Wednesday, Trump administration officials were grilled about the decision to defer large parts of the 737's safety certification to Boeing.

Transportation Secretary Elaine Chao said Wednesday that she found it "very questionable" that safety systems were not part of the standard package offered by Boeing on its 737 Max jets.

"It is very questionable if these were safety oriented additions why they were not part of the required template of measures that should go into an airplane," she said in testimony before the Senate, where she was appearing to answer questions about her annual budget request.

But Chao defended the decision of the Federal Aviation Administration not to ground Boeing's signature plane after the first of two fatal crashes. [8]
Conclusion. Thus, the characteristic features of the author's journalism are: a clear author's position on the proposed issue (author's comments); individual stylistic features of the construction of the text (the author's style) ; non trivial approach to covering the topic; feedback from the audience. That is why at the mention of the past important events there are always remembered the individual names of the authors who covered them. Therefore, the event is perceived due to the author. The above-described linguistic features of news notes allow us to conclude that the informative function, which has a clear advantage here over the impact function, creates an information substyle of Internet journalism, characterized by a high degree of standardization. This is the next step in our research.

\section{REFERENCES}

1. Akopov A.M. Socio-cultural and legal problems of online journalism // Accents: New in mass communication. Almanac №1-2, 2003

2. Kakhuzheva (Tkhabisimova) Z. G. Linguistic and stylistic peculiarities of a news note // Bulletin of Adyghe State University. Series 2: Philology and art history. 2012

3. Kikhtan V.V. Information Technologies in Journalism. Rostov n / D: Phoenix, 2004. - 160 p. (Ser .:

Higher education).

4. Solganik G. The authorasastyle-forming category of journalistic text // BulletinMosk.un-that. Ser. 10. Journalism. M., 2001. № 3

5. Tonkih. I. Internet journalism Genre in Internet [Electronic resource]:primary meeting /I. Tonkikh.-Electronic Dani.-
Zaporizhzhya: ZNTU, 2017.-1electron.wholesale Disc(DVDROM);12see Nazvaztit. screen.

6. Fomicheva .I. Sociology of online media: study guide / Fomicheva I.D. - M.: Faculty of Journalism, Moscow State University. MvLomonosov, 2005. 79s. Recommended by the Academic Council of the Faculty of Journalism of Moscow State University, ed. filol. Sciences M.M. Lukin.

7. Schelkunova E.S. Publicistic text in the system of mass communication: studies. allowance. Voronezh: Birth speech, 2004. 194 p.

8. https://edition.cnn.com/2019/03/27/economy/boeing-softwarefix-737-max/index.html 